\title{
THE CULTURE OF INFORMATION: Ubiquitous Computing and Representations of Reality ${ }^{1}$
}

\author{
Paul Dourish \\ University of California, Irvine \\ Irvine, CA U.S.A.
}

Weiser's original discussion of the emerging age of ubiquitous computing was formulated largely in technological terms, as an extrapolation of continuing trends in the design and capabilities of computer hardware, software, and infrastructure. Implicit in this transformation of computational platforms, though, lies a transformation of the ways in which we encounter, engage with, and experience interactive information systems. As computation becomes increasingly embedded in the everyday world, our experience of information systems increasingly draws upon our experience of the real world itself, in all its physical, social, and cultural manifestations. The nature of what, in my own work, I term "embodied interaction" is not merely a physical embodiment, but an experiential embodiment that draws as much on the social as the physical in the ways in which we encounter the world and find it meaningful.

The idea at work here is that our experience of the world is richer, more natural, more nuanced and in some ways more effective than our interaction with the disembodied information in conventional computer systems. So, in his classic article, Weiser (1991) makes the telling remark that there is more information available to us in a walk in the woods than there is when we sit in front of a computer, our quintessential information processing system. By this, he wants to draw attention to the complexity and clumsiness of traditional computer interfaces, and the obstacles that they put in the way of the tasks that they are designed to support. However, his analogy raises a separate question, which he does not explore but I wish to here: why should we think of a walk in the woods as an information exercise, and what happens when we do?

The use of "information" as a mass noun is a relatively new phenomenon (Day 2001). Information had previously referred to the process or activity of informing or of being informed; to "receive information" was to participate in a process, much as one

'Copyright (C) 2005, Paul Dourish. Used with permission. 
might "receive confirmation." More recently, though, and particularly since the development of electronic information systems, our idea of information has changed, and we start to think of information as a thing in itself (Buckland 1991). So, in casting the embodied experience of the physical world in information terms, Weiser isn't breaking new ground; rather, he is following in a distinctly twentieth century tradition of searching for mathematical models of everyday life. In particular, the notion of information as a fundamental coin of the realm is part of a broader movement from the analog world to the digital, a movement that also involves a radical conceptual shift. When digital information processing machines were first introduced, they were dubbed "electronic computers." Although it is difficult to remember now, this was not a new term; "computers" was a term in common use, referring to the people (largely women) who performed rote calculations for the production of, for example, artillery targeting tables. The new machines, then, were electronic computers in the sense that they were electronic equivalents of (human) computers. Indeed, these new machines were generally understood and thought of as equivalent or similar to organic entities; they were, as so many newspaper headlines declared, "giant electronic brains."

In the subsequent years, and in particular with the emergence of cognitive science in the 1960s and 1970s, a fascinating conceptual shift took place. The fundamental perspective of cognitive science was that the mind could be understood in computational terms; that information flow, information processing, and information storage were the terms in which human cognitive activity could be modeled and understood. In other words, where previously we had understood computer systems to be derivative of human behavior, this model was now inverted; humans were now to be understood as a form of computer. Where once the computer was a giant electronic brain, now the brain was a biological computer. Accordingly, the rhetoric of information processing that was part and parcel of the world of electronic computation became the model by which human experience was to be understood; memory could be understood in terms of storage capacity, and rationality in terms of operations performed per second.

As analog devices have increasingly been replaced with digital counterparts, this information rhetoric has continued to spread. Recent developments in ubiquitous computing - the same set of trends that Weiser was discussing - have been part of this shift. Ubiquitous computing sees the movement of computation away from traditional computer systems and into the everyday world, through the development of networked embedded and wearable technologies. So, the world becomes a site of computation and an object of informational representation. We start to understand and model the world in information terms, as suggested by Weiser's remark that even a walk in the woods can be thought of it terms of its information content.

This seemingly innocuous statement is actually a quite radical one. It equates information with experience (or, rather, suggests that experience is founded upon information.) It is a way of using the concept of information that is both practiced and culturally bound. Information, in other words, is a cultural category; an element of a broad cultural understanding of reality. We can see this best, perhaps, by looking for the boundaries. If a walk in the woods can be thought of in information terms, how about a loving relationship? How about a performance of Beethoven? How about an insult, or a physical exchange of blows? The very fact that we would inherently resist a suggestion that these experiences can be modeled and understood in terms of 
information flows, storage, and processing highlights the way in which information is a cultural category, one that reflects the ways in which we understand and think about the world and our place within it.

So, ubiquitous computing, as a research program, arises within this broader context which sees information as an object that can be uncovered, moved around, and processed, rather than as a reflection of social and cultural relations.

We can see this at work in the notion of "ambience," such as the explorations of ambient information displays originated at MIT and the European "ambient intelligence" program. Ambience draws our attention to distinctions between focus and periphery (Brown and Duguid 1994) and the different ways in which information can be incorporated into an environment. But at the same time, it retains this same focus on information as an object while obscuring other ways in which environments might be informative. For example, return to Weiser's question of the experience of space, but think about it from different points of view. Aboriginal Australians, for example, have an experience of their landscape that is quite different from Western traditions (Stanner 1958). They experience the landscape in terms of a series of ritual responsibilities, not just for its upkeep, but for its very existence. The link between the Dreaming and the everyday world, the link that connects the land to the processes that brought it into existence and continue to shape it, must be actively maintained. The land is experienced, too, in terms of clans and lineage groups; the very features of the land link it to the Dreamtime actions of totemic creatures whose continuance is marked by patterns of land occupancy and responsibility. Finally, the land is experienced in terms of historical events; the actions of humans leave their marks, both physically and spiritually, on the land. Any movement through the landscape, and any experience of it, is cast in these terms. There is much more to be "read" in the land than purely physical form, but this is an aspect of daily experience, not an information experience to be thought of as looking it up in a dictionary. Indeed, the land may be experienced first in terms of its symbolic meaning and only secondly in terms of its physical form. The landscape is experienced as meaningful, not read or processed as information.

If we think of information as a cultural category, then, and of informating - that is, the process of reading aspects of everyday life in information terms - then it is sensible to ask what is being done by that process. Arguably, the process of describing aspects of the world in information terms makes them amenable to information-based processes; to the forms of representation, transformation, and processing associated with a variety of technical disciplines. In recent discourse, though, the informating of everyday life brings it particularly into the domain of computer scientists and of commercial information systems providers. If your problem can be conceived of as an information problem, then it is a problem that Microsoft and IBM can help to solve. If your problem can be conceived of as an information problem, then it is a problem that a computer scientist can address. If your problem can be conceived of as an information problem, then it is one on which Moore's Law will naturally have its effect. What is at stake, then, is the right to create, define, and lay claim to both problems and solutions.

More broadly, this alternative view suggests some important research challenges for ambient intelligence. Recent shifts in how we think about technology and experience as embodied phenomena (Dourish 2001) mark not only an increasing concern with the physical aspect of interaction design, although that has clearly been an important 
issue and a significant element of the ubiquitous computing program, but a quite different reading of interaction beyond the information processing approach. Research in ubiquitous computing has often made use of social science methods as ways of understanding settings into which technology might be introduced; our considerations here suggest that we might fruitfully also use these approaches to investigate how these settings are understood by the people who populate and enact them. If information, ubiquity, and intelligence are cultural categories, then how can the relationship between technology and social and cultural practice be reimagined?

\section{REFERENCES}

Brown, J. S., and Duguid, P. "Borderline Issues: Social and Material Aspects of Design," Human-Computer Interaction (9), 1994, pp. 3-36.

Buckland, M. "Information as Thing," Journal of the American Society of Information Science (42:5), 1991, pp. 351-260.

Day, R. The Modern Invention of Information: Discourse, History, and Power, Carbondale, IL: Southern Illinois University Press, 2001.

Dourish, P. Where the Action Is: The Foundations of Embodied Interaction, Cambridge, MA: MIT Press, 2001.

Stanner, W. "The Dreaming," in Reader in Comparative Religion: An Anthropological Approach, W. A. Lessa and E. Z. Zohn (Eds.), Evanston, IL: Row, Peterson, 1958, pp. $513-$ 523

Weiser, M. "The Computer for the $21^{\text {st }}$ Century," Scientific American (265:3), 1991, pp. 94-104.

\section{ABOUT THE AUTHOR}

Paul Dourish is an associate professor in the Donald Bren School of Information and Computer Sciences at the University of California, Irvine, and associate director of the Irvine Division of the California Institute for Telecommunications and Information Technology. His primary research interests are in the areas of ubiquitous computing, computer-supported cooperative work, and human-computer interaction. $\mathrm{He}$ is especially interested in the foundational relationships between social scientific analysis and technological design. His book, Where the Action Is: The Foundations of Embodied Interaction, was published by MIT Press in 2001 ; it explores how phenomenological accounts of action can provide an alternative to traditional cognitive analysis for understanding the embodied experience of interactive and computational systems.

Before coming to UCI, he was a senior member of research staff in the Computer Science Laboratory of Xerox PARC; he has also held research positions at Apple Computer and at Rank. Xerox EuroPARC. He holds a Ph.D. in Computer Science from University College, London, and a B.Sc. (Hons) in Artificial Intelligence and Computer Science from the University of Edinburgh. 


\section{Part 2}

\section{Individual}

\section{Consequences}

